University of Nebraska - Lincoln

DigitalCommons@University of Nebraska - Lincoln

Educational Psychology Papers and

Publications

Educational Psychology, Department of

2008

"You're So Gay!": Do Different Forms of Bullying Matter for Adolescent Males?

\author{
Susan M. Swearer Napolitano \\ University of Nebraska-Lincoln, sswearernapolitano1@unl.edu \\ Rhonda K. Turner \\ University of Nebraska-Lincoln \\ Jami E. Givens \\ University of Nebraska-Lincoln \\ William S. Pollack \\ Harvard Medical School/McLean Hospital
}

Follow this and additional works at: https://digitalcommons.unl.edu/edpsychpapers

Part of the Educational Psychology Commons

Swearer Napolitano, Susan M.; Turner, Rhonda K.; Givens, Jami E.; and Pollack, William S., "'You're So Gay!": Do Different Forms of Bullying Matter for Adolescent Males?" (2008). Educational Psychology Papers and Publications. 153.

https://digitalcommons.unl.edu/edpsychpapers/153

This Article is brought to you for free and open access by the Educational Psychology, Department of at DigitalCommons@University of Nebraska - Lincoln. It has been accepted for inclusion in Educational Psychology Papers and Publications by an authorized administrator of DigitalCommons@University of Nebraska - Lincoln. 
School Psychology Review,

2008, Volume 37, No. 2, pp. 160-173

\title{
"You're So Gay!": Do Different Forms of Bullying Matter for Adolescent Males?
}

\author{
Susan M. Swearer, Rhonda K. Turner, and Jami E. Givens \\ University of Nebraska-Lincoln
}

\author{
William S. Pollack \\ Harvard Medical School/McLean Hospital
}

\begin{abstract}
This study examined effects of adolescent males' perceptions of being bullied because of verbal taunts related to gender nonconformity (i.e., "They say I'm gay"). Participants included 251 ninth- $(n=77)$, tenth- $(n=96)$, and eleventh- $(n=78)$ grade students in a private, all-male college preparatory school. Participants were divided into two groups based on whether they were bullied by being called gay. Out of the 251 participants, 121 (48\%) reported having been bullied and $127(50 \%)$ stated that they had not been bullied during the past year ( $2 \%$ did not report). Of the 121 participants who had been bullied, 32 (26\%) reported that they had been bullied because others called them gay (Group 1) and $89(74 \%)$ reported that they had been bullied for other reasons, exclusive of being called gay (Group 2). Consistent with predictions, the boys who were bullied because they were called gay experienced greater psychological distress, greater verbal and physical bullying, and more negative perceptions of their school experiences than boys who were bullied for other reasons. Implications for school-based intervention services for bullying are discussed.
\end{abstract}

Bullying is a pervasive problem faced by U.S. youth. In an often-cited national survey of U.S. youth in Grades 6-10, Nansel and colleagues (2001) found that $29.9 \%$ of students reported moderate or frequent involvement in bullying, either as a bully, a victim, or as both (i.e., bully-victim). Although the research literature on bullying in the United States has expanded exponentially in the last two decades, there is a paucity of empirical literature examining bullying related to gender nonconformity, particularly among adolescent males (Espelage \& Swearer, 2003). The research that has been conducted on gender nonnormative behavior (i.e., being seen as feminine for males and masculine for females) has typically been examined among gay, lesbian, bisexual, and transgendered (GLBT) youth.

\section{Bullying and GLBT Youth}

Estimates of the number of GLBT youth in the United States vary, but most researchers

The authors thank all the students and their parents who participated in this research project as well as the excellent suggestions made by three anonymous reviewers.

Correspondence regarding this article should be addressed to Susan M. Swearer, 40 Teachers College Hall, Department of Educational Psychology, University of Nebraska-Lincoln, Lincoln, NE 68588-0345; E-mail: sswearer@unlserve.unl.edu 
believe that between 5 and $6 \%$ of youth identify into one of these categories. Overall, then, as many as $\mathbf{2}$ million school-age children in the United States are dealing with issues related to their sexual orientation (Human Rights Watch, 2001). However, regardless of actual sexual orientation, Rivers, Duncan, and Besag (2007) reported that over 1.6 million public school students are bullied because of either actual or perceived sexual orientation.

What is known about bullying of sexual minority youth is discouraging. In a study conducted by Human Rights Watch from October 1999 to October 2000, during which 140 GLBT youth between the ages of 12 and 21 from California, Georgia, Kansas, Massachusetts, New York, Texas, and Utah were interviewed, youth reported persistent and severe homophobic bullying including taunts, property damage, social exclusion, and physical attacks. Although some GLBT students in the United States experience a positive, welcoming environment at school, these experiences appear to be rare. According to the data from the Human Rights Watch study, GLBT youth are nearly three times as likely as their heterosexual peers to have been assaulted or involved in at least one physical fight in school, are three times as likely to have been threatened or injured with a weapon at school, and are nearly four times as likely to have skipped school because they felt unsafe (Human Rights Watch, 2001).

Pilkinton and D'Augelli (1995) surveyed 194 gay, lesbian, and bisexual youth between the ages of 15 and 21 . Of that sample, $30 \%$ of the males and $35 \%$ percent of the females reported having been harassed or verbally abused in school because of their sexual orientation. Twenty-two percent of the males and $29 \%$ of the females in the study reported having been physically hurt by a peer in school (Pilkington \& D'Augelli, 1995). Conversely, in the Nansel et al. (2001) study of the general school population, $8.5 \%$ of students reported being bullied "sometimes," and $8.4 \%$ reported being bullied "once a week or more" (p. 2096). Thus, it appears that GLBT youth experience bullying and/or harassment to a greater degree than non-GLBT youth.
In a series of related studies of lesbians', gay men's, and bisexual men's and women's accounts of victimization at school, Rivers $(2000,2001,2004)$ concluded that experiences of bullying were pervasive among GLBT youth and were related to higher rates of posttraumatic stress and depression in adulthood and to absenteeism during the school years. In Rivers' 2001 retrospective survey of 60 GLBT adults, participants reported that bullying based on their sexuality started early, at around 10 or 11 years old, and tended to continue for more than 4 years. Approximately two-thirds of the participants reported that bullying had occurred weekly or several times a week (Rivers, 2001). Of 116 participants in Rivers' 2000 study, $72 \%$ reported having feigned illness or skipped school to avoid abuse based on their sexual orientation. Rivers (2001) found that psychological intimidation (threatening looks or stares), public ridicule, and the theft of personal belongings were all associated with absenteeism. Rivers (2000) also emphasized that the GLBT adults who reported absenteeism from school were more likely to report having experienced suicidal ideation and suicide attempts than were those who reported that harassment did not affect school attendance.

Although what we know about bullying of sexual minority youth is discouraging, recent litigation may help reverse this phenomenon. A lawsuit awarded a Kansas teenager $\$ 250,000$ as a result of gender-based bullying (Gender Public Advocacy Coalition, 2005). Dylan Theno, a former Tonganoxie, Kansas, student, successfully sued the Tonganoxie school district for failure to take appropriate action in response to his complaints of sexual harassment. Dylan Theno testified that he had repeatedly been called "faggot," "flamer," and "masturbater boy" since seventh grade. This homophobic bullying continued until his junior year, at which point he left school to complete his GED. Riki Wilchins, the Executive Director of the Gender Public Advocacy Coalition, stated:

Dylan Theno's story is dangerously common. Boys who do not measure up to someone else's idea of a "real man" are under the 
constant scrutiny and criticism of their peers. This ruling is a wake-up call to school districts and parents across the country. The old "boys will be boys" attitude toward bullying and harassment is just not going to cut it anymore. (Gender Public Advocacy Coalition, 2005)

This lawsuit may help in forcing educators, parents, and students to recognize that certain verbal taunts have lasting, deleterious effects.

\section{Bullying and Gender Nonconformity Among Youth}

In their conclusion that verbal harassment of GLBT students is a serious problem in U.S. high schools and middle schools, Human Rights Watch (2001) noted that nearly every one of the 140 GLBT youth interviewed for their study reported having been the victim of verbal or other nonphysical harassment in school because of their sexual orientation or other students' perception of their sexual orientation. Indeed, bullying with content based on gender nonconformity is not exclusively targeted at youth who are gay, lesbian, bisexual, or transgendered.

Regardless of their actual sexual orientation, youth find it particularly distressing to be harassed based on perceived sexual orientation. The American Association of University Women Education Foundation (1993) found that $86 \%$ of students, virtually evenly matched among girls and boys, stated that they would be very upset if they were identified by their peers as homosexual. Boys in particular reacted strongly to harassment targeting their sexuality, reacting to such verbal abuse even more strongly than to physical attacks.

Kimmel and Mahler (2003) noted that in nearly all accounts of random school shootings from 1982 to 2001, the male shooters (in every case the shooter was male) reported having been harassed "for inadequate gender performance" (p. 1440), for which the authors coined the term gay-baiting. In reviewing written news reports of the shootings, the authors noted that the shooters were not victimized because they were actually gay, but rather because they were "different from other boys-shy, bookish, honor students, artistic, musical, theatrical, nonathletic, 'geekish,' or weird" (p. 1445). Noting the geographic locations of these events, primarily white, middleclass, rural or suburban schools, not inner cities more associated with violence, Kimmel and Mahler suggested that attitudes toward gender nonconformity, particularly for boys, becomes a foundation for bullying and, ultimately in some tragic cases, for lethal school violence. Supporting the finding that gender nonconformity is linked to deleterious outcomes for adolescent males, Young and Sweeting (2004) found that "gender atypical" boys were victimized, lonely, had fewer male friends, and experienced greater psychological distress than "gender typical" boys. Thus, behavior that is gender non-normative appears to be a salient developmental issue for boys.

Phoenix, Frosh, and Pattman (2003) interviewed 78 boys ages 11-14 from 12 different London schools. Interviews were conducted individually and in groups. Boys expressed concern that participating in the interviews would expose them to ridicule and perceived this as a threat to their masculinity. They were more willing to discuss emotions and comport themselves seriously in individual interviews, and nearly a third of them stated a preference for the individual interviews. The boys noted that referring to others with homophobic epithets was commonplace but reacted emotionally to the notion that such comments might be aimed at themselves. Phoenix and colleagues note:

Boys had to be careful about what they did or said for fear of being called gay or effeminate-both of which they invariably found upsetting. In this sense, their identities were "policed" in that they were scrutinized for lack of conformity to a core, heterosexual notion of appropriate masculinity and "deviations" were punished through name-calling and/or ostracism. (p.188)

Further, the boys who were interviewed reported that their teachers did not label homophobic name-calling as bullying and did not punish the perpetrators (Phoenix et al., 2003). The lack of adult sanctions for homophobic name-calling may serve to support and maintain these behaviors. This tacit support on 
the part of adults may be an important factor in the development of attitudes that children have toward the acceptability of bullying behaviors.

\section{Moral Disengagement as a Mechanism for Bullying}

Given that the extant literature on bullying that is gender non-normative is still largely focused on describing the victimization of GLBT youth, few models have been suggested to explain its occurrence and its extension to gender nonconformity. A possible explanation for the targeting of behaviors that are gender non-normative can be derived from Bandura's theory of moral disengagement. Bandura, Barbaranelli, Caprara, and Pastorelli (1996) posit that individuals develop culturally sanctioned beliefs about how they and others should behave, and these beliefs generally guide behavior. At times, however, individuals can selectively disengage from these beliefs through a variety of cognitive processes termed moral disengagement. One of these mechanisms involves dehumanizing or blaming the victim. Through dehumanization, individuals can justify engaging in negative or mean behavior because the target is seen as deserving of the negative comments and/or behavior. Attributing blame to the victim is another way to justify engaging in negative behavior. Labeling a peer as a member of a particular sexual orientation may not only be part of the content of bullying (i.e., calling a peer "gay"), but it also may facilitate its escalation through moral disengagement. Although there has been limited empirical support about the role of moral disengagement in bullying among youth (Hymel, Rocke-Henderson, \& Bonanno, 2005), it is well documented that youth who bully others report prebullying beliefs, which support their behavior.

\section{Youth Attitudes and Perceptions About Bullying}

Indeed, children's attitudes and perceptions of bullying are recognized as for understanding this phenomenon. Attitudes towards bullying are defined as students' moral judg- ments regarding the appropriateness of bullying and related behaviors (Salmivalli \& Voeten, 2004). Rigby and Slee (1991) examined Australian students' attitudes towards victims of bullies, ages 6-16 years, using a 20 -item previctim scale. They found that the majority of children were opposed to bullying and were more likely to be supportive of victims. Gender differences were found, with girls significantly more supportive of victims than were boys. However, the trend toward support for victims reversed with age, with older children reporting a negative view of victims of bullying and admiration of the bullies.

Normative beliefs about bullying behavior may serve to support the perpetuation of bullying among school-aged youth. Oliver, Hoover, and Hazler (1994) found that approximately $45 \%$ of boys and $30 \%$ of girls believed that bullying had an educative purpose. That is, bullying was done to "teach" the victims about behaviors that are unacceptable to the group. In addition, $64 \%$ of students surveyed said victims brought teasing on themselves and $61 \%$ of students felt bullying helped the victim by making him or her "tougher." In addition, both boys and girls stated that bullies had a higher social status than did victims. Given peer support for bullying behaviors in school, the link between school climate and prebullying attitudes is important to include in research on school bullying.

Prebullying attitudes were also found with a middle school sample of students. Swearer and Cary (2003) found that from the sixth to the eighth grade, attitudes toward bullying were fairly consistent, with a trend towards having more favorable attitudes toward bullying by eighth grade. Bullying behavior may be influenced by contextual effects and normative beliefs students have about behavior, which may play a role in predicting student's future bullying behavior (Salmivalli \& Voeten, 2004). Attitudes are context related and vary according to certain conditions, (e.g., bullying in a peer group vs. alone) and according to who holds them. The need to understand the social context in relation to peer relations and social behavior, especially with bullying, 
has become increasingly clear (Espelage, Holt, \& Henkel, 2003). Even if children report they do not like peers who bully, they may be impressed by them because they are perceived as brave, strong, and self-confident (Garbarino \& DeLara, 2002; Olweus, 1978).

There is increasing evidence that prebullying attitudes are significant predictors of future bullying involvement. Those children with the most positive attitudes towards bullying were nominated most often as bullies by their peers (Boulton, Bucci, \& Hawker, 1999); they also self-reported that they engaged in bullying (Boulton, Trueman, \& Flemington, 2002; Salmivalli \& Voeten, 2004) or assisted the bully (Salmivalli \& Voeten, 2004). On the other hand, antibullying attitudes, or moral disapproval of bullying, were related to defending the victims and avoiding bullying situations (Salmivalli \& Voeten, 2004).

Students' perceptions of why they were bullied or why they bullied others were examined across the sixth, seventh and eighth grades (Swearer \& Cary, 2003). External attributes, such as being different, being weak, and wearing certain clothes, were consistently cited across the status groups as reasons youth were bullied. Bullies endorsed victims' physical traits, such as the way they talk, the clothes they wear, or being weak, as reasons for bullying. Reasons victims reported they were bullied included getting good grades, being weak, being overweight, being different, and wearing certain clothes. Bully-victims endorsed the same reasons as both victims and bullies. Youth not involved in bullying reported that students were bullied because they were weak, overweight, different, and wore certain clothes. Victims and students not involved in bullying held the least favorable attitudes towards bullying. Relatedly, in a study by Dill, Vernberg, Fonagy, Twemlow, and Gamm (2004), youth who experienced an increase in victimization or who believed aggression was an acceptable form of social behavior reported an increased negative affect (Dill et al., 2004).

Although previous research has shown that students who identify as GLBT are likely to be bullied because of their sexual minority status (Pilkington \& D'Augelli, 1995; Rivers, $2000,2001,2004$ ), no studies have examined the effect of bullying that is gender non-normative (i.e., being called gay) on the psychosocial functioning of adolescent males, irrespective of their actual sexual orientation. Kimmel and Mahler (2003) suggested that to identify the effect of homophobic bullying, researchers need to focus on the content of bullying, not simply on its presence or absence (i.e., looking at which names a youth was called rather than the fact that he or she was called a name). Thus, the purpose of this preliminary investigation was to examine the effects of being called gay on the psychosocial functioning of adolescent males. Based on Young and Sweeting's (2004) finding that gender-atypical boys experienced greater psychosocial distress than gender-typical boys, we hypothesized that boys who were bullied by being called gay would display greater internalizing problems, would report having experienced both verbal and physical bullying, and would hold more negative perceptions of their school environment compared to boys who were bullied for other reasons (exclusive of being called gay).

\section{Method}

\section{Participants}

Participants were 251 ninth- $(n=77)$, tenth- $(n=96)$, and eleventh- $(n=78)$ grade students in a private, all-male college preparatory school in an urban Midwestern city. The boys in the study were ages $14(7 \%), 15$ (31\%), $16(35 \%), 17(26 \%)$, and $18(1 \%)$. Most of the participants were European American (90\%); $5 \%$ were Latino/Hispanic, $2 \%$ were African American, 2\% were Biracial, and $1 \%$ were Asian American. The majority of the participants did not receive any financial aid to help pay for tuition (69\%), but $25 \%$ of the participants did receive some form of financial aid (6\% did not report). In addition, the majority of the participants $(82 \%)$ lived with both parents and received no special education services (94\%). Thus, the sample was predominately European American, from middle- to upper-middle-class families. 
Out of the 251 participants, 121 (48\%) reported being bullied during the past school year and $127(50 \%)$ stated that they had not been bullied during the past year ( $2 \%$ did not respond). Participants were divided into two groups based on being bullied because of perceptions of gender nonconformity by being called gay. Of the 121 participants who had been bullied, $32(26 \%)$ reported that the main reason they had been bullied was because "They say I'm gay" (Group 1) and 89 (74\%) reported that the main reason they had been bullied was for other reasons, exclusive of being called gay (Group 2). The top five reasons for being bullied endorsed by Group 2 were: "I get good grades" (28\%); "They think I'm a wimp" (27\%); "I am different" (23\%); "They think my friends are weird" (16\%); and "The clothes I wear" (15\%).

\section{Procedures}

Data for this study were part of a larger longitudinal study examining bullying and victimization in a sample of adolescent males attending an all-male private high school. Starting in 2003, parents of all incoming ninth-graders were given a description of the longitudinal study on bullying and peer relationships and were given a consent form to sign if they agreed to allow their son to participate. Out of all the ninth-grade students, the parental participation rate was $39 \%$ in $2003,40 \%$ in 2004 , and $32 \%$ in 2005 . Thus, a little over one-third of the ninth-grade parents consented to have their sons participate in the larger longitudinal study on bullying and peer relationships. We attributed the low active parental consent rate to the fact that participants missed instructional time to complete the measures. Parents might also have hesitated to sign consent for 4 years, which was the duration of the larger longitudinal study. The current study used a cross-sectional portion of the data collected in Spring 2005 and focused on relationships between being called gay and psychological experiences among ninth-, tenth-, and eleventh-grade boys.

\section{Measures}

Bully/victim experiences. The Bully Survey (Swearer, 2005) is a four-part, 31question survey that queries students regarding their experiences with bullying, perceptions of bullying, and attitudes toward bullying. Bullying is defined, using the U.S. Department of Health and Human Services, Health Resources and Services Administration definition of bullying (with permission, S. Limber, personal communication, March 2004) in each section of the survey as follows:

Bullying happens when someone hurts or scares another person on purpose and the person being bullied has a hard time defending himself or herself. Usually, bullying happens over and over and includes: (a) Punching, shoving and other acts that hurt people physically; (b) spreading bad rumors about people; (c) keeping certain people out of a "group"; (d) teasing people in a mean way; and (e) getting certain people to "gang up" on others.

Respondents answer questions about when they were victims of bullying during the past year, when they observed bullying behavior among their peers during the past year, and when they bullied other students during the past year. For the present study, the item "Why do you think you were bullied?" was used to group the participants who endorsed "Because they say I'm gay." There are 31 reasons respondents can check for why they were bullied. Respondents can check more than one reason for reasons why they felt they were bullied. A 14-item Bullying Attitudinal Scale is included, with higher total scores on the Bullying Attitudinal Scale considered to indicate attitudes supportive of bullying. In the present study, the internal consistency reliability using coefficient alpha was .71 for the Bullying Attitudinal Scale total score.

Verbal and Physical Bullying Scale (VPBS; Swearer, 2005). An 11-item scale assessing both verbal and physical bullying is subsumed in Part A of the Bully Survey (described earlier). Seven items assess verbal bullying and four items assess physical bullying. All items are scored on a 5-point scale (never happened to always happens). Internal consis- 


\section{Table 1}

Factor Analysis of the Verbal and Physical Bullying Experiences Scale

\begin{tabular}{lrr}
\hline \multicolumn{1}{c}{ Item } & Verbal & Physical \\
\hline $\begin{array}{l}\text { Made fun of me } \\
\text { Said mean things behind }\end{array}$ & .82 & \\
$\quad$ my back & .78 & \\
$\begin{array}{l}\text { Called me names } \\
\text { Won't let me be a part of }\end{array}$ & .73 & \\
$\quad$ their group & .68 & \\
Nobody would talk to me & .68 & \\
Wrote bad things about me & .63 & \\
$\begin{array}{l}\text { Played jokes on me } \\
\text { Attacked me }\end{array}$ & .55 & \\
$\begin{array}{l}\text { Pushed or shoved me } \\
\text { Broke my things }\end{array}$ & & .86 \\
Said they will do bad & & .84 \\
$\quad$ things to me & & .65 \\
\% Variance explained & 34.23 & 23.43 \\
\hline
\end{tabular}

tency reliability for the present study was .87 for the VPBS total score. A principal components factor analysis using varimax rotation was conducted for the 11 items of the VPBS. As shown in Table 1, this analysis yielded a two-factor solution, with expected items loading onto the Physical Bullying $(\alpha=.79)$ and Verbal Bullying ( $\alpha=.85$ ) factors with no cross-loadings.

Aggression symptoms. The Aggression Questionnaire (AQ; Buss \& Warren, 2000 ) is a self-report measure, consisting of 34 items designed to assess anger and aggression in individuals ranging from 9 to 88 years old. The AQ has five subscales: Physical Aggression, Verbal Aggression, Anger, Hostility, and Indirect Aggression. A total aggression score is derived by summing the raw scores for the five subscales. Each item of the $A Q$ describes a characteristic related to aggression. Participants are asked to read each item and rate how much each item is similar to themselves on a 5-point scale: $1=$ Not at all like me to $5=$ Completely like me. AQ Total scores of 110 or greater ( $\mathrm{T}$ score $=60$ ) are considered to indicate high levels of aggression. In the present study, the internal consis- tency reliability using coefficient alpha was .90 for the total score.

Anxiety symptoms. The Multidimensional Anxiety Scale for Children (MASC; March, 1997) is a self-report measure assessing major dimensions of anxiety in children ages 8-19 years. The MASC consists of 39 items and includes four basic scales (Physical Symptoms, Harm Avoidance, Social Anxiety, and Separation/Panic) that when combined create a scale measuring total anxiety. Individuals are asked to rate the severity of each item based on a 4-point Likert-type scale. The MASC has demonstrated acceptable internal consistency reliability for all main factors and subfactors, including a total score coefficient alpha of .90 (March, Parker, Sullivan, Stallings, \& Conners, 1997). In addition, the MASC has demonstrated satisfactory to excellent test-retest reliability (March, Sullivan, \& Parker, 1999). In the present study, the internal consistency reliability using coefficient alpha was .91 for the total score.

Depression symptoms. The Children's Depression Inventory (CDI; Kovacs, 1992) is the most commonly used self-report measure of depression for children 7-17 years of age. The CDI consists of 27 items designed to assess the overt symptoms of childhood depression. The CDI measures five highly correlated factors: Negative Mood, Interpersonal Problems, Ineffectiveness, Anhedonia, and Negative Self-Esteem. These five factors are combined to yield one higher order factor of childhood depression. Participants are asked to rate the severity of each item on a 3-point scale of $0-2$ during the two weeks before testing. Total scores of 19 or greater are considered to indicate potential depression (Stark, 1990). The CDI has demonstrated acceptable internal consistency and test-retest reliability as well as convergent validity (Kovacs, 1992). In the present study, the internal consistency reliability using coefficient alpha was .86 for the total score.

Hopelessness symptoms. The Hopelessness Scale for Children (HSC; Kazdin, French, Unis, Esveldt-Dawson, \& Sherick, 
1983) was modeled after the Beck Hopelessness Scale for Adults (Beck, Weissman, Lester, \& Trexler, 1974) and is written at about a second-grade reading level. Hopelessness is defined as negative expectations that one holds towards oneself and towards the future (Kazdin et al., 1983). According to past research (Abramson, Metalsky, \& Alloy, 1989; Beck et al., 1974; Kazdin et al., 1983), hopelessness is likely to precede depression and suicidal ideation. The HSC is comprised of 17 true-false items that describe feelings of hopelessness or negative expectations for the future. A higher total score indicates greater feelings of hopelessness. In the present study, the internal consistency reliability using coefficient alpha was .68 for the total score.

Internal-external locus of control. The Children's Nowicki-Strickland InternalExternal Scale (CNSIE; Nowicki \& Strickland, 1973) is a 40-item self-report instrument for children ages 9-18 that is designed to measure whether a child believes that reinforcement comes to him or her by chance or fate (external locus of control) or because of his or her own behavior (internal locus of control). The range of scores is from 0 to 40 , with higher scores reflecting a more external locus of control. The CNSIE has been used extensively and has been found to be a reliable and valid measure of the locus of control construct within children and adolescents (Nowicki \& Strickland, 1973). Split-half internal consistency ranged between .68 and .81 from children in Grades 3-12, and test-retest reliability ranged between .63 and .71 (Nowicki \& Strickland, 1973). Analyses of gender differences have demonstrated that girls score significantly higher total internal locus of control scores than boys (Manger \& Eikeland, 2000). In the present study, internal consistency using coefficient alpha was .75.

Perceptions of school climate. The Thoughts About School (TAS; Song \& Swearer, 1999) is a 34-item scale with four factors: Positive Student and Teacher Interactions, Negative Student and Teacher Interactions, Bullying Support, and Vandalism. This
Table 2

\section{Descriptive Statistics for Dependent} Variables

\begin{tabular}{lcc}
\hline \multicolumn{1}{c}{ Variable } & Group & Mean $(S D)$ \\
\hline Aggression & 1 & $83.12(20.65)$ \\
& 2 & $79.85(17.52)$ \\
Anxiety & 1 & $46.87(18.32)$ \\
& 2 & $36.92(15.84)$ \\
Depression & 1 & $14.87(11.23)$ \\
& 2 & $9.14(7.79)$ \\
Hopelessness & 1 & $3.25(2.68)$ \\
& 2 & $2.68(2.35)$ \\
Internal/external & 1 & $17.94(6.26)$ \\
& 2 & $13.00(5.38)$ \\
School climate & 1 & $91.46(10.98)$ \\
& 2 & $100.93(10.70)$ \\
Verbal/physical & 1 & $30.84(8.08)$ \\
& 2 & $21.24(6.52)$ \\
\hline
\end{tabular}

Note. Aggression = AQ total score; anxiety = MASC total score; depression = CDI total score; hopelessness = HSC total score; internal/external = CNSIE total score; school climate = TAS total score; verbal/physical = VPBS total score; Group $1=$ bullied because they say I'm gay; Group 2 = bullied for reasons other than being called gay.

scale is based on a previous instrument (Kasen, Johnson, \& Cohen, 1990) that describes aspects of school climate hypothesized to be relevant to students' emotional and behavioral development. Students are asked to rate each item in terms of how they think it reflects their school on a 4-point scale from $1=$ Totally False to $4=$ Totally True. Higher scores reflect more positive views of school climate. In the present study, the internal consistency reliability using coefficient alpha was .73 for the total score.

\section{Results}

\section{Preliminary Analyses}

Means and standard deviations for the dependent variables are reported in Table 2. Although these data were drawn from a community sample, interesting comparisons can be made with the normative data from the standardization samples for the published 
Table 3

Bivariate Correlations for Dependent Variables

\begin{tabular}{lccccccc}
\hline & 1 & 2 & 3 & 4 & 5 & 6 & 7 \\
\hline 1. Anxiety & - & $.37^{* *}$ & $.41^{* *}$ & $.17^{* *}$ & -.12 & $.25^{* *}$ & $.27^{* *}$ \\
2. Depression & $.37^{* *}$ & - & $.47^{* *}$ & $.55^{* *}$ & $-.38^{* *}$ & $.56^{* *}$ & $.49^{* *}$ \\
3. Verbal/physical & $.41^{* *}$ & $.47^{* *}$ & - & $.18^{*}$ & $-.41^{* *}$ & $.36^{* *}$ & $.31^{* *}$ \\
4. Hopelessness & $.17^{* *}$ & $.55^{* *}$ & $.18^{*}$ & - & $-.35^{* *}$ & $.41^{* *}$ & $.24^{* *}$ \\
5. School climate & -.12 & $-.38^{* *}$ & $-.41^{* *}$ & $-.35^{* *}$ & - & $-.51^{* *}$ & $-.30^{* *}$ \\
6. Internal/external & $.24^{* *}$ & $.55^{* *}$ & $.36^{* *}$ & $.41^{* *}$ & $-.51^{* *}$ & - & $.42^{* *}$ \\
7. Aggression & $.23^{* *}$ & $.49^{* *}$ & $.31^{* *}$ & $.24^{* *}$ & $-.30^{* *}$ & $.42^{* *}$ & - \\
\hline
\end{tabular}

Note. Anxiety = MASC total score; depression = CDI total score; verbal/physical = VPBS total score; hopelessness = HSC total score; school climate $=$ TAS total score; internal/external = CNSIE total score; aggression $=\mathrm{AQ}$ total score. $* * p<.01$.

$* p<.05$.

measures. Both T scores for Groups 1 and 2 on the AQ were lower than the T score for adolescent males in the standardization sample ( $T$ scores of 49 and 48 , respectively, compared to a $T$ score of 55). On the MASC, the mean for Group $1(M=46.87)$ was higher than the mean of 37.91 for adolescent males in the standardization sample (which was consistent with the mean of Group 2). On the CDI, adolescent males in the standardization sample had a mean of 11.36 , which was higher than the mean of Group $2(M=9.14)$ and lower than the mean of Group 1 (14.87). The $\chi^{2}$ analyses were run to see whether any demographic variables might account for group differences on the dependent measures. Participants who were bullied because of being called gay (Group 1) and participants who were bullied for other reasons (Group 2) did not differ in terms of race, grade, receiving financial aid, age, living arrangement, or special education status. Bivariate correlations among the dependent variables are listed in Table 3.

\section{Psychological Factors and Being Bullied Because of Being Called Gay}

As previously described, we identified two groups of victims: those who reported being bullied because of being called gay (Group 1), and those who were bullied for reasons other than being called gay (i.e., getting good grades, being wimpy, being different, having weird friends, and wearing certain clothes; Group 2). A multivariate analysis of variance was conducted to examine whether the psychological effect of being bullied because of being called gay was more significant for those victimized boys compared with boys who reported being bullied for other reasons. Significant differences were found between the two groups on the dependent measures, Wilks's lambda $=.75, F(6,114)=6.14, p<$ .01 .

\section{Discriminant Analysis: Psychological Predictors}

Follow-up discriminant analysis was conducted to see whether the six predictorsaggression, anxiety, depression, hopelessness, locus of control, and perceptions of school climate-could predict group membership. The overall Wilks's lambda was significant, Wilks's lambda $=.76, \chi^{2}(6, N=251)=$ $32.48, p<.01$, indicating that the predictors differentiated the two groups. The standardized canonical discriminant function coefficients and the correlations (loadings) between predictors and the discriminant function are presented in Table 4. Based on these loadings, school climate, anxiety, depression, and locus of control demonstrated the strongest relation- 
Table 4

Standardized Discriminant Function
Coefficients and Correlations for
Dependent Measures

\begin{tabular}{lcc}
\hline & $\begin{array}{c}\text { Standardized } \\
\text { Canonical } \\
\text { PISCRIM } \\
\text { Predictors }\end{array}$ & $\begin{array}{c}\text { Coefficients } \\
\text { Structure } \\
\text { Matrix }\end{array}$ \\
\hline School climate $^{a}$ & .63 & .68 \\
Internal/external $^{a}$ & -.48 & -.68 \\
Depression $^{a}$ & -.27 & -.51 \\
Anxiety $^{a}$ & -.43 & -.47 \\
Hopelessness $_{\text {Aggression }}$ & .28 & -.18 \\
& .35 & -.14 \\
\hline
\end{tabular}

${ }^{a}$ Coefficients greater than .33 (10\% of variance) in the structure matrix are considered salient (Tabachnick \& Fidell, 2007).

ship with the discriminant function. The means on the discriminant function are consistent with this interpretation. Boys who were bullied because others called them gay reported more negative perceptions of school climate, higher anxiety, higher depression, and an external locus of control $(M=-0.94)$. Boys who were bullied for reasons other than being called gay endorsed more positive perceptions of school climate, lower anxiety, lower depression, and a more internal locus of control $(M=0.33)$.

\section{Typology of Bullying Among the Two Groups}

We were interested in whether being bullied because of being called gay would be related to both physical and verbal forms of bullying. A multivariate analysis of variance was conducted to examine whether boys who were bullied because of being called gay were more likely to experience both verbal and physical forms of bullying. Significant differences were found among the two groups on the dependent measures, Wilks's lambda = $.64, F(11,109)=5.58, p<.01$.

\section{Table 5}

Standardized Discriminant Function Coefficients and Correlations for Verbal and Physical Forms of Bullying

\begin{tabular}{|c|c|c|}
\hline Predictors & $\begin{array}{c}\text { Standardized } \\
\text { Canonical } \\
\text { DISCRIM } \\
\text { Coefficients }\end{array}$ & $\begin{array}{l}\text { Structure } \\
\text { Matrix }\end{array}$ \\
\hline \multicolumn{3}{|l|}{ Verbal bullying } \\
\hline $\begin{array}{l}\text { Won't let me be a } \\
\text { part of their group }\end{array}$ & .47 & .70 \\
\hline Called me names ${ }^{a}$ & .54 & .69 \\
\hline Made fun of $m e^{a}$ & -.00 & .64 \\
\hline $\begin{array}{l}\text { Nobody would talk to } \\
\text { me }^{a}\end{array}$ & .28 & .63 \\
\hline $\begin{array}{l}\text { Wrote bad things } \\
\text { about } \mathrm{me}^{a}\end{array}$ & .15 & .52 \\
\hline $\begin{array}{l}\text { Said mean things } \\
\text { behind my back }\end{array}$ & -.05 & .49 \\
\hline Played jokes on me & -.20 & .30 \\
\hline \multicolumn{3}{|l|}{ Physical bullying } \\
\hline Do bad things to me ${ }^{a}$ & .23 & .55 \\
\hline Attacked me $\mathrm{e}^{a}$ & .11 & .36 \\
\hline Pushed or shoved me & -.02 & .29 \\
\hline Broke my things & -.12 & .25 \\
\hline
\end{tabular}

${ }^{a}$ Coefficients greater than .33 (10\% of variance) in the structure matrix are considered salient (Tabachnick \& Fidell, 2007).

\section{Discriminant Analysis: Typology of Bullying}

Follow-up discriminant analysis was conducted to see whether 11 predictors-7 verbal forms of bullying and 7 physical forms of bullying-would predict group membership. The overall Wilks's lambda was significant, Wilks's lambda $=.64, \chi^{2}(11, N=$ 251) $=50.70, p<.01$, indicating that overall predictors differentiated the two groups. The standardized canonical discriminant function coefficients and the correlations (loadings) between predictors and the discriminant function are presented in Table 5. Based on these loadings, all forms of verbal and physical bullying except for having jokes played on them, being pushed or shoved, of having their things bro- 
ken demonstrated the strongest relationship with the discriminant function. The means on the discriminant function are consistent with this interpretation. Boys who were bullied because others call them gay reported greater group exclusion, name-calling, being made fun of, being ignored, having bad things written about them, having mean things said about them behind their backs, having bad things done to them, and being attacked $(M=1.24)$. Boys who were bullied for reasons other than being called gay reported less verbal and physical bullying $(M=-0.44)$.

\section{Discussion}

This study examined whether adolescent males who reported being bullied by being called gay would experience greater psychological impairment and more physical and verbal forms of bullying than boys who were bullied for other reasons. Results suggested that boys who are bullied because they are called gay can be differentiated from boys who are bullied for other reasons. Specifically, preliminary findings suggest that boys who are bullied by being called gay endorse more negative perceptions of school climate, experience higher anxiety and depression, and display a more external locus of control than boys who are bullied for other reasons. In addition, boys who are bullied by being called gay experience greater verbal and physical bullying than boys who are bullied for other reasons.

This study extends previous research on the deleterious effects of being bullied due to actual or perceived sexual minority status (Rivers, 2001; Young \& Sweeting, 2004) and found preliminary support for negative effects as a result of being called gay, irrespective of whether the participant was in fact a member of a sexual minority group. Further, results from this study support previous research, which has found that being a target of rumors is associated with psychosocial maladjustment (Nishina, Juvonven, \& Witkow, 2005) and that cognitive attributions are an important mediator between victimization and negative psychosocial consequences (Dill et al., 2004).
It has been argued that boys' fear of being teased for not being "man enough" or a "real boy" has led to young males' diminished academic self-efficacy, increased rates of depression and suicide, and a general constriction of emotional expression and interpersonal connections, which are essential to healthy developmental functioning in our society (Pollack, 1998, 2000, 2006; Resnick et al., 1997). This study lends preliminary support to the assertion that being bullied by being called gay has negative effects on boys' psychosocial functioning.

Pollack $(1998,2006)$ suggests that even in our present environment of expanded gender roles for girls, boys are still locked in a "gender straitjacket," enforced by the cultural shaming of what he describes as the "Boy Code." This code dictates to young males that the expression of any form of vulnerability is tantamount to femininity and such "female traits" are then redefined, in a taunting manner, as evidence of being gay. The clear message is that being perceived as gay means that the individual is defective and dysfunctional. Consequently, a vicious cycle of verbal bullying and bravado ensues wherein boys tease other boys about the full extent of their masculinity, in part to eschew being called gay themselves. This is a culturally proscribed socialization process of restrictive masculinity, leaving straight boys at risk for both being bullied and bullying in return, while gay young males are left to feel less than whole, not because of their sexual identity but because of the restrictive and, at times, damaging code, which too often is written off as just "boys will be boys."

\section{Limitations and Directions for Future Research}

Several limitations of the current investigation warrant attention and provide directions for future research. It will be important for future research to assess whether boys who are called gay are in fact coming to terms with sexual identity issues. It could be that boys who are engaged in the process of defining their sexual orientation are at greater risk for 
psychological impairment than are boys who know they are heterosexual. In this investigation, we did not assess whether the participants self-identified as a member of a sexual minority group or were struggling with defining their sexual identity. In addition, this study is correlational; causality is thus unknown until we conduct a longitudinal investigation of these possible associations. Generalization is also limited because the sample in this study was predominantly European American and middle class, and attended a private school in the Midwest. However, although this is a limitation in terms of generalizing the results to other populations, it is interesting that these boys, who have many advantages by attending a private high school, did report significant internalizing difficulties and problems associated with being called gay. The consent rates ranged from $32 \%$ to $40 \%$ across the years, which is another limitation. All measures were self-report; common method variance is another problem. However, despite these limitations, this study furthers our awareness of the harmful effects of being called gay among adolescent males. Future research should also examine homophobic bullying in nongenderconforming girls. Are the detrimental effects of being called gay the same for victimized girls as they are for victimized boys?

\section{Implications for School-Based Bullying Prevention and Intervention}

Results from this study further extend our awareness that the occurrence of bullying, whether physical or verbal, is harmful to victims. It is becoming more important for researchers and educators to realize the deleterious effects of verbal bullying in developing bullying interventions. In fact, a recent lawsuit was filed in California when a female student was disciplined for saying "That's so gay" to her classmates (Associated Press, 2007). Thus, although it is important to recognize when and if bullying is occurring, it is also vital to determine which forms the bullying takes (physical, verbal, cyber), as well as the content of the bullying (e.g., "gay baiting" or other taunts). However, regardless of the typology of the bullying, students' participation in bullying begins with their attitudes and perceptions toward bullying.

Examining the cognitions and attitudes of students toward bullying may assist in developing effective prevention and intervention programs to reduce bullying behaviors (Doll \& Swearer, 2006; Orpinas \& Horne, 2006; Swearer \& Cary, 2003). The role of students' attitudes and their participation in bullying is an important component of prevention and intervention programming, as prebullying attitudes have been found to be moderately, but significantly, correlated with bullying behaviors (Boulton et al., 1999). Normative beliefs supported through peer groups and contextual situations affect bullying as children may bully others or do little to prevent bullying because of their high acceptance levels of bullying or because of their negative views of victims. It is important to address the rigidity of gender expectations in the school environment to minimize the perpetration and effect of bullying based on gender nonconformity.

Starting in elementary school, school personnel need to develop a climate supportive of students who are not constricted by traditional gender norms (i.e., boys who are in band and theater; girls who lift weights; Kimmel \& Mahler, 2003). Although much of the research on attitudes toward bullying has found that students are generally not supportive of bullying behaviors when asked (Baldry, 2004; Boulton et al., 1999; Boulton et al., 2002; Menesini et al., 1997; Rigby \& Slee, 1991), there is a decrease in the willingness to intervene against bullying as students enter adolescence (Menesini et al., 1997). Results from this study suggest that not only should observers of bullying intervene when they witness physical bullying behaviors; they should intervene when they hear verbal bullying.

\section{References}

Abramson, L. Y., Metalsky, G. I., \& Alloy, L. B. (1989). Hopelessness depression: A theory-based subtype of depression. Psychological Review, 96, 358-372.

American Association of University Women Educational Foundation. (1993). Hostile Hallways: The AAUW Survey on Sexual Harassment in America's Schools. Washington, DC: Author. 
Associated Press. (2007, February 28). 'That's so gay' prompts student lawsuit. Retrieved March 1, 2007, from http://www.msnbc.msn.com/id/17388702/?GTI=9145

Baldry, A. C. (2004). 'What about bullying?' An experimental field study to understand students' attitudes towards bullying and victimization in Italian middle schools. British Journal of Educational Psychology, 74(4), 583-598.

Bandura, A., Barbaranelli, C., Caprara, G. V., \& Pastorelli, C. (1996). Mechanisms of moral disengagement in the exercise of moral agency. Journal of Personality and Social Psychology, 71(2), 364-374.

Beck, A. T., Weissman, A., Lester, D., \& Trexler, L. (1974). The measurement of pessimism: The Beck Hopelessness Scale. Journal of Consulting and Clinical Psychology, 42, 861-865.

Boulton, M., Bucci, E., \& Hawker, D. (1999). Swedish and English secondary school pupils' attitudes towards, and conceptions of, bullying: Concurrent links with bully/victim involvement. Scandinavian Journal of Psychology, 40(4), 277-284.

Boulton, M., Trueman, M., \& Flemington, I. (2002). Associations between secondary school pupils' definitions of bullying, attitudes towards bullying, and tendencies to engage in bullying: Age and sex differences. Educational Studies, 28(4), 353-370.

Buss, A. H., \& Warren, W. L. (2000). The Aggression Questionnaire manual. Los Angeles: Western Psychological Services.

Dill, E. J., Vernberg, E. M., Fonagy, P., Twemlow, S. W., \& Gamm, B. K. (2004). Negative affect in victimized children: The roles of social withdrawal, peer rejection, and attitudes toward bullying. Journal of Abnormal Child Psychology, 32(2), 159-173.

Doll, B. J., \& Swearer, S. M., (2006). Cognitive-behavioral interventions for participants in bullying and coercion. In R. B. Mennuti, A. Freeman, \& R. W. Christner (Eds.), Cognitive-behavioral interventions in educational settings: A handbook for practice (pp. 183201). New York: Routledge.

Espelage, D. L., Holt, M. K., \& Henkel, R. R. (2003). Examination of peer-group contextual effects on aggression during early adolescence. Child Development, $74(1), 205-220$.

Espelage, D. L., \& Swearer, S. M. (2003). Research on school bullying and victimization: What have we learned and where do we go from here? School Psychology Review, 32(3), 365-383.

Garbarino, J., \& DeLara, E. (2002). And words can hurt forever: How to protect adolescents from bullying, harassment, and emotional violence. New York: The Free Press.

Gender Public Advocacy Coalition. (2005). Sticks and stones break bones-and words hurt too: Bullied Kansas teen wins $\$ 250 \mathrm{~K}$ in lawsuit against school district. Retrieved August 16, 2005, from http://www.gpac.org

Human Rights Watch. (2001). Hatred in the hallways: Violence and discrimination against lesbian, gay, bisexual, and transgender students in the U.S. New York: Author.

Hymel, S., Rocke-Henderson, N., \& Bonanno, R. A. (2005). Moral disengagement: A framework for understanding bullying among adolescents. Journal of Social Sciences, 8, 1-11.

Kasen, S., Johnson, J., \& Cohen, P. (1990). The impact of school emotional climate on student psychopathology.
Journal of Abnormal Child Psychology, 18(2), 165177.

Kazdin, A. E., French, N. H., Unis, A. S., Esveldt-Dawson, K., \& Sherick, R. B. (1983). Hopelessness, depression, and suicidal intent among psychiatrically disturbed inpatient children. Journal of Consulting and Clinical Psychology, 51(4), 504-510.

Kimmel, M. S., \& Mahler, M. (2003). Adolescent masculinity, homophobia, and violence: Random school shootings, 1982-2001. American Behavioral Scientist, 46(10), 1439-1458.

Kovacs, M. (1992). Children's Depression Inventory (CDI): Technical manual. North Tonowanda, NY: Multi-Health Systems.

Manger, T., \& Eikeland, O. J. (2000). On the relationship between locus of control, level of ability and gender. Scandinavian Journal of Psychology, 4I(3), 225-229.

March, J. S. (1997). The Multidimensional Anxiety Scale for Children: Technical manual. North Tonawanda, NY: Multi-Health Systems.

March, J. S., Parker, J. D., Sullivan, K., Stallings, P., \& Conners, C. K. (1997). The multidimensional anxiety scale for children (MASC): Factor structure, reliability, and validity. Journal of the American Academy of Child \& Adolescent Psychiatry, 36, 554-565.

March, J. S., Sullivan, K., \& Parker, J. (1999). Test-retest reliability of the Multidimensional Anxiety Scale for Children. Journal of Anxiety Disorders, 13(3), 349358.

Menesini, E., Eslea, M., Smith, P. K., Genta, M. L., Giannetti, E., Fonzi, A., et al. (1997). Cross-national comparison of children's attitudes towards bully/victim problems in school. Aggressive Behavior, 23, 245257.

Nansel, T. R., Overpeck, M., Pilla, R. S., Ruan, W. J., Simons-Morton, B., Scheidt, P. (2001). Bullying behaviors among US youth: Prevalence and association with psychosocial adjustment. Journal of the American Medical Association, 285, 2094-2100.

Nishina, A., Juvonen, J., \& Witkow, M. R. (2005). Sticks and stones may break my bones, but names will make me feel sick: The psychosocial, somatic, and scholastic consequences of peer harassment. Journal of Clinical Child and Adolescent Psychology, 34(1), 37-48.

Nowicki, S., \& Strickland, B. R. (1973). A locus of control scale for children. Journal of Consulting and Clinical Psychology, 40, 148-151.

Oliver, R., Hoover, J. H., \& Hazler, R. (1994). The perceived roles of bullying in small-town Midwestern schools. Journal of Counseling \& Development, 72, 416-420.

Olweus, D. (1978). Aggression in the schools: Bullies and whipping boys. Washington, DC: Hemisphere.

Orpinas, P., \& Horne, A. M. (2006). Bullying prevention: Creating a positive school climate and developing social competence. Washington, DC: American Psychological Association.

Phoenix, A., Frosh, S., \& Pattman, R. (2003). Producing contradictory masculine subject positions: Narratives of threat, homophobia and bullying in 11-14 year old boys. Journal of Social Issues, 59(1), 179-195.

Pilkington, N. W., \& D'Augelli, A. R. (1995). Victimization of lesbian gay and bisexual youth in community settings. Journal of Community Psychology, 23(1), 3356. 
Pollack, W. S. (1998). Real boys: Rescuing our sons from the myths of boyhood. New York: Owl Books.

Pollack, W. S. (2000). Real boys' voices. New York: Random House.

Pollack, W. S. (2006). The 'war' for boys: Hearing 'real boys' voices, healing their pain. Professional Psychology: Research and Practice, 37, 190-195.

Resnick, M., Bearman, P., Blum, R., Bauman, K., Jones, J., Tabor, J., et al. (1997). Protecting adolescents from harm: Findings from the National Longitudinal Study on Adolescent Health. Journal of the American Medical Association, 278(10), 823-832.

Rigby, K., \& Slee, P. T. (1991). Bullying among Australian school children: Reported behavior and attitudes toward victims. Journal of Social Psychology, 131(5), 615-627.

Rivers, I. (2000). Social exclusion, absenteeism and sexual minority youth. Support for Learning, 15(1), 13-18.

Rivers, I. (2001). Retrospective reports of school bullying: Stability of recall and its implications for research. British Journal of Developmental Psychology, 19 , $129-142$.

Rivers, I. (2004). Recollection of bullying at school and their long-term implications for lesbians, gay men, and bisexuals. Crisis, 25(4), 169-174.

Rivers, I., Duncan, N., \& Besag, V. E. (2007). Bullying: A handbook for educators and parents. Westport, CT: Praeger.
Salmivalli, C., \& Voeten, M. (2004). Connections between attitudes, group norms, and behaviour in bullying situations. International Journal of Behavioral Development, 28(3), 246-258.

Song, S. Y., \& Swearer, S. M. (1999). Thoughts about school. Unpublished manuscript, The University of Nebraska-Lincoln.

Stark, K. D. (1990). Childhood depression: School-based intervention. New York: The Guilford Press.

Swearer, S. M., \& Cary, P. T. (2003). Perceptions and attitudes toward bullying in middle school youth: A developmental examination across the bully/victim continuum. Journal of Applied School Psychology, $19(2), 63-79$.

Swearer, S. M. (2005). The Bully Survey. Unpublished manuscript. The University of Nebraska-Lincoln.

Tabachnick, B. G., \& Fidell, L. S. (2007). Using multivariate statistics (5th ed.). Boston, MA: Allyn \& Bacon.

Young, R., \& Sweeting, H. (2004). Adolescent bullying, relationships, psychological well-being, and genderatypical behavior: A gender diagnosticity approach. Sex Roles, 50, 525-537.

Date Received: February 22, 2007

Date Accepted: January 21, 2008

Action Editor: Thomas Power

Susan $\mathrm{M}$ Swearer, $\mathrm{PhD}$, is an associate professor of school psychology at the University of Nebraska-Lincoln and the codirector of the Nebraska Internship Consortium in Professional Psychology. Her research interests center around the examination of psychological and environmental influences that contribute to bullying behavior among school-aged youth and promoting models of data-based decision making in bullying prevention and intervention.

Rhonda K. Turner, MA, is a doctoral candidate in school psychology at the University of Nebraska-Lincoln, and is completing her predoctoral internship at the Munroe Meyer Institute in Omaha, Nebraska. Her research interests include social-cognitive aspects of childhood bullying and aggression, and the efficacy of integrated behavioral health services in primary pediatric care.

Jami E. Givens, MA, is a doctoral candidate in the School Psychology program at the University of Nebraska-Lincoln. Her research interests include relational aggression and victimization, gender differences in aggression, and internalizing disorders.

William S. Pollack, $\mathrm{PhD}$, is an assistant clinical professor of psychology in the Department of Psychiatry, Harvard Medical School, and the Director of the Centers for Men and Young Men at McLean Hospital, a teaching affiliate of Harvard Medical School. His research interests center around the "new" psychology of men and boys; boys' socialization via the "boy code," which leads to homophobia, bullying, and school failure; new ways to diagnose and treat depression in boys and men; and helping young men to discover and speak their genuine voices of empathy and connection. 